\title{
The Development of Network based Composite Power quality Regulation Device
}

\author{
Weiqiang Fan, Ying Lei, Jing Zhu, Luo Li, Shuai Niu \\ New energy technology research department, Xi’an High Voltage Apparatus Research Institute Co. Ltd, Xi'an, China \\ Email: 312509892@qq.com
}

Received March, 2013

\begin{abstract}
First, the paper analyzes the advantages and disadvantages of all kinds of reactive power compensation technology, and then proposes a principle and integrated control strategy of the composite operation of TSC and SVG, also the paper designs and develops the main controller of Network based composite power quality regulation device, based on RTDS, the real-time digital simulation model of The Device is established, and finally the prototype of the device is developed with the function of filter and split-phase compensation. The main controller determines the cooperative operation of both TSC and SVG, and the switching strategy of TSC. The simulation result in RTDS can verify the precision of the measure system and the validity of the control logic, the prototype has finished the type test according to the national standard.
\end{abstract}

Keywords: Network Based; Composite Power Quality Regulation Device; Reactive Power Compensation Technology; RTDS

\section{Introduction}

With the rapid development of national economy, the amount and variety of power consumption equipment connected to the distribution network are also increasing, which causes the growing decline in the power quality characterized by the large amount of reactive power and serious harmonic pollution, so the effective method in improving power quality is to adopt reactive power compensation technology and harmonic suppression technology [1,2].

After decades of development, a variety of reactive power compensation devices have emerged. The cost and technical content of MSC is low but its poor dynamic compensation effect may bring many negative influence behind; The advantage of TSC is low cost, the single-tuned filter, large compensation capacity, split-phase compensation etc, but it can only achieve the step regulation of reactive power but cannot suppress voltage flicker; The TCR+FC type has the dynamic and smooth regulating characteristics, but it can produce large harmonics and the grid voltage have a impact on its compensation capacity, which usually cause high fault rate. The SVG can realize continuous reactive compensation and suppress voltage flicker, but its disadvantages lie in high cost and high-power switch device's impact on its compensation capacity [3-5].

Xi'an High Voltage Apparatus Research Institute Co.
Ltd has developed a novel via compensator- — Network based composite power quality regulation device, which consists of several TSC banks and a SVG, by making full use of TSC's long-term stable reactive power compensation and power harmonic suppression and SVG's instant fast reactive power compensation, the rapidly continuous large-capacity reactive compensation can be realized, so this device not only compensates the reactive power and harmonic but also has a high performance price ratio compared to counterpart device.

\section{Device Function Requirement and Construction Principle Design}

\subsection{Function Requirement}

In order to improve power factor more effectively and stabilize grid voltage, and then improve the grid power quality, The Device should have following basic functions.

1) Dynamically continuous reactive power compensation, the power factor is always close to 1 when the device's capacity meets the demands.

2) The function of specific harmonic filter, the grid-side harmonic current injected by user can meet national harmonic standard when the device's capacity meets the demands.

3) The ability to compensate unbalanced three-phase reactive power (split-phase compensation). 
4) The function of over-current, over-voltage, voltageabsent, under-voltage, phase-loss etc, protections and SVG's self-start.

5) The function of temperature controlled protection.

6) Equipped the intelligent human-computer terminal device, it can measure and display voltage, active power, reactive power, power factor and the operation state of SVG and TSC bank.

7) Equipped the field bus communication interface, it can achieve remote monitoring function.

The Device is mainly used in the industrial enterprise of low voltage distribution power system, it can compensate load reactive power, enhance the grid power factor, stabilize the grid voltage, at the same time reduce the harmonic current injected into the grid, with the intention of grid energy-saving and improvement of power supply quality. The Device mainly used in the following situations:

1) The rapidly changing load involving in the distribution system. Apply TSC/SVG to compensate the rapidly changing reactive power and suppress voltage fluctuation and voltage flicker.

2) A large number of AC and DC motor speed regulation equipment, induction-heating power supply, controllable resistance furnace, single crystal furnace, electroplating and electrolysis rectifier power etc involving in the distribution system. Apply filter branch to compensate rapidly changing reactive power and suppress the harmonics.

3) A large number of switching power supply, computer involving in the distribution system, since the electronic equipment groups generate serious harmonic interference, we adopt filter branch not only to compensate load reactive power but also to prevent grid harmonic amplification, achieve high precision requirement of reactive power compensation.

\subsection{Principle}

The Device has the advantages of low cost, rapidly continuous reactive power compensation, because it has the function of both TSC and SVG:SVG can provide small-scaled capacitive and inductive reactive power and then attain the precision compensation of reactive power, at the same time it can suppress grid voltage fluctuation, so it is the continuous-time subsystem in the device; TSC can provide large-scaled capacitive reactive power, adjustment by grades it can attain the rough compensation, at the same time it has the advantages of split-phase compensation, harmonic prevention in the branch series with reactors, so it is the discrete-time subsystem in the device; Both can operate together by the main controller to have the advantages and disadvantages complementary of TSC and SVG, with the intention of rapidly continuous large-scaled reactive power compensation in low cost[6-8].

The Device can attain continuous compensation between maximum capacitive reactive power and maximum inductive reactive power through the composite operation of both TSC and SVG. When the grid-side reactive power demand values locate between N-TSC banks and (N+1)-TSC banks, switch N-TSC banks and then the SVG compensates the rest reactive power demands, with the intention of rapidly continuous largescaled reactive power compensation in low cost.

\subsection{Structure Design}

The basic structure of The Device is in Figure 1, N-TSC banks and a SVG are connected to the grid, the capacity of TSC and SVG depends on the different working condition, the main controller firstly detects grid voltage, current, then calculates present grid power(involving active power and reactive power),after analyzing SVG's operation state, it finally gives the switching order to compensate the large amount of reactive power in the grid and ultimately improve power factor as well as power quality.

Considering that TSC can compensate three-phase balance or unbalanced reactive power and reactor in series with TSC branch as filter, we use some TSC as three-phase compensation groups and the rest as spitphase compensation groups, and connect reactors separately in series with TSC branch to filter harmonics. In the way, The Device has the function of three-phase compensation, spilt-phase compensation, filter, harmonic prevention etc.

\section{The Main Controller Design}

\subsection{Functional Design}

According to the system structure of The Device, the main controller has following feature to ensure proper operation:

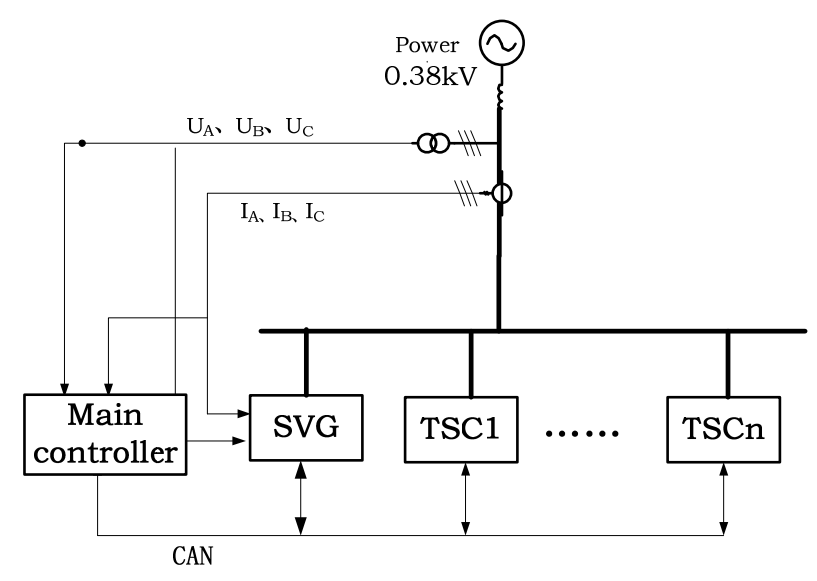

Figure 1. The structure diagram. 
1) Detect three-phase voltage and current in the grid and then calculate present active power, reactive power and power factor.

2) Properly communicate with SVG, TSC controllable chips, inquire SVG and TSC present state and then display to the user.

3) Correctly give TSC switching order according to the defined workflow, reduce the reactive power supply as low as possible and improve power factor.

4) Equip the intelligent human-computer interface of the exchange, can modify operation mode and some functional data, and external communication mode including CAN, RS232 and RS485 etc.

The main controller consists of controlled chip and display terminal. Figure $\mathbf{2}$ is the function diagram of the main controller designed in the paper: it firstly realizes the sampling of voltage, current, temperature, then calculates present reactive power, active power in the grid, finally gets the TSC switching order after analysis; The main controlled can properly communicate with TSC and SVG, and then give order to them. It can communicate with touch screen and display present operation state; also it can instruct present operation state through $\mathrm{I} / \mathrm{O}$ interface.

\subsection{Man-Computer Interface Design}

The touch screen is the man-computer interface of total system and play an important role in the system .For one thing, the touch screen can display the operation state of total system, then it provide user with grid voltage, active power, reactive power, power factor, TSC switching state and SVG operation state etc. when the device is running. For another, it is convenient for the user to control the operation state of every module through touch screen; also the user can do the TSC switching, SVG's start-stop setting and parameter setting in the touch screen as required.

As shown in Figure 3, the main controller firstly samples the grid voltage, current, based on the instantaneous reactive power theory, it calculates active power and reactive power of every phase in the grid, then after TSC split-phase, three-phase compensation strategy analysis, it concludes the TSC switching results, finally it sends the order to the TSC banks through communication interface and completes the TSC switching operation. In this way, the controller not only can finish intelligent switching control but also instruct the SVG to compensate the rest reactive power in the grid.

\section{Test}

According to the national standard, the composite power quality regulation device completes the type test. The device is shown in Figure 4

\subsection{Inrush Current Test}

Figure $\mathbf{5}$ is the inrush current test wave recorder measured by the oscilloscope when the capacitor switches in the TSC branch. When the TSC receives the switching order, it switches at the $\mathrm{U}_{\mathrm{T}}$ (the voltage between thyristor's A anode and $\mathrm{K}$ cathode) zero-crossing instant, the maximum inrush current peak value is about $75 \mathrm{~A}$, and the steady-state value is about $50 \mathrm{~A}$, the inrush current value is about two times of the steady-state value.

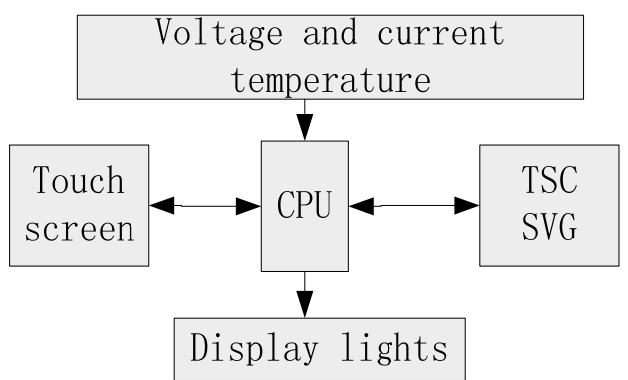

Figure 2. The function diagram of main controller.

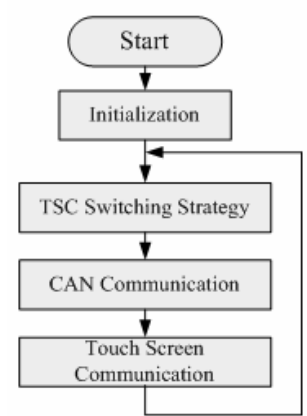

(a) main program flow

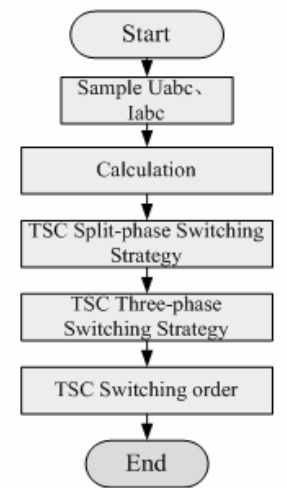

(b) TSC switching strategy flow
Figure 3. The flow chart.

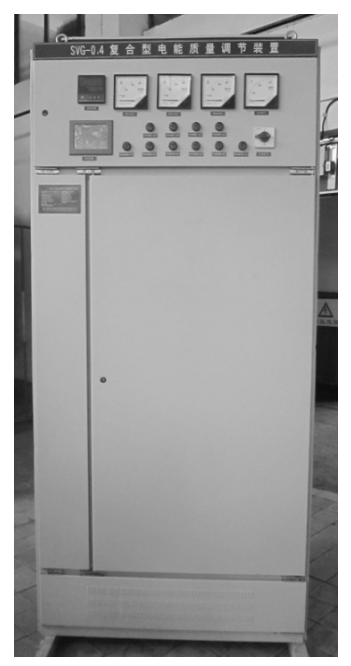

Figure 4. Network based Composite Power quality Regulation Device. 


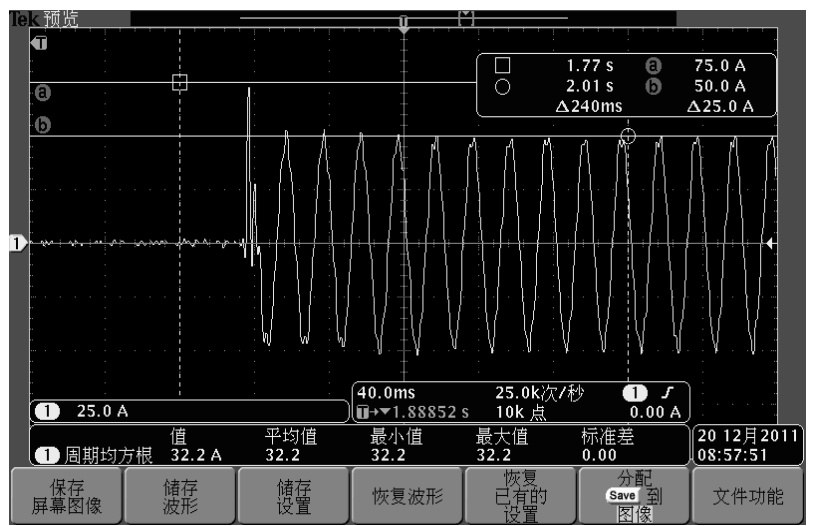

Figure 5. TSC Inrush current test.

\subsection{Main Controller Test}

The test is the composite compensation functional test of both TSC and SVC branch, The Device's model is established in the RTDS system, when the reactive power of the load varies within device's capacity, the main controller regulates both TSC banks and SVG to work together harmoniously, which can make The Device's rapidly continuous compensation possible and at the same time improve the power factor as well as power quality.

In the process of the test, by changing the reactive power of the load, we observe the TSC banks switching changes, the reactive power generated by SVG and the composite compensation effect.

\subsubsection{Experimental Results of Three-phase Balanced Load System}

The simulated waveform is shown in Figure 6 when the TSC was in the under compensation state. When the inductive load attained 50kvar, TSC banks were switched on, and TSC current and SVG current remained in phase which lead the grid voltage by 90 degrees, then the TSC was put into undercompensated operation while the SVG generated capacitive reactive power; after compensation, grid current and grid voltage were in phase and the power factor attained 1.00 .

Note: the waveform from top to bottom are grid voltage, grid current, TSC branch current, SVG current output respectively.

The simulated waveform is shown in Figure 7 when the TSC was in the overcompensation state. When the inductive load attained 80kvar, TSC banks were switched on, and TSC current and SVG current were of the opposite phase, TSC current led the grid voltage by 90 degrees while SVG current lagged the gird voltage by 90 degrees, then the TSC was put into overcompensated operation while the SVG generated inductive reactive power; after composite compensation, grid current and grid voltage were in phase and the power factor attained
1.00 .

The composite compensation functional experiments above have verified that the main controller can effecttively cooperate and control the composite compensation of both TSC and SVG and ultimately attain the optimal compensation effect.

\subsubsection{Experimental Results of Three-phase Unbalanced Load System}

The experiment can assess the function that main controller automatically switch on-off the spilt-phase compensated capacitor branch of TSC under unbalanced load system, in the process of simulation, we can adjust the unbalanced load as required and observe the spiltphase compensation capacitor's switching state according to the every single-phase loads, at the same time calculate the degree of unbalancedness of the system.

The unbalanced loads had a limited impact on the grid voltage because of the large power supply capacity, in the test we adopted the current unbalanced level which are defined by the formula in the IEEE Std.936-1987, as follows: using mean value of three-phase current, the three-phase voltage unbalance level can be expressed by:

$$
\% P V U R_{936}=\frac{\max \left(U_{a}, U_{b}, U_{c}\right)-\min \left(U_{a}, U_{b}, U_{c}\right)}{U_{a v}} \times 100 \%
$$

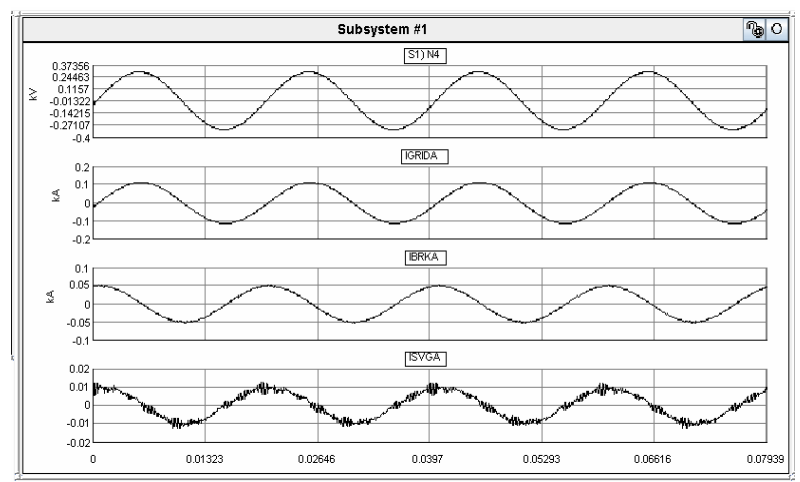

Figure 6. The simulated waveform when the TSC was put into undercompensated operation.

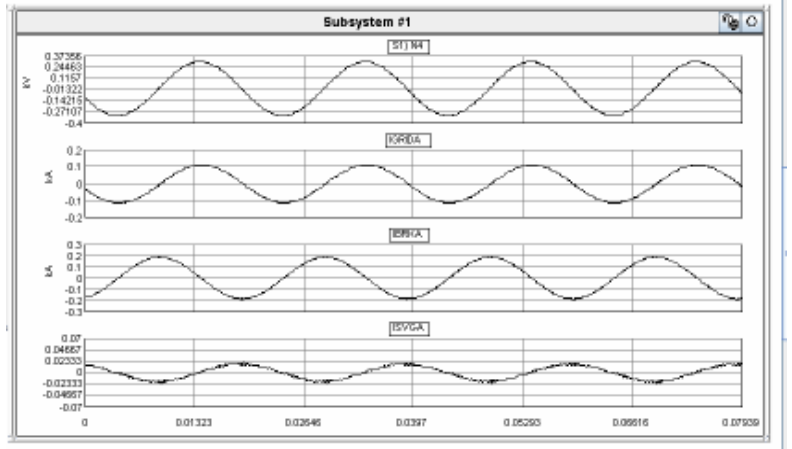

Figure 7. The simulated waveform when the TSC was put into overcompensated operation. 
Table 1. Data sheet of TSC split-phase compensation test.

\begin{tabular}{|c|c|c|c|c|c|c|c|c|c|c|c|c|c|}
\hline \multicolumn{2}{|c|}{ Load input } & \multicolumn{3}{|c|}{ A1 } & \multicolumn{3}{|c|}{ A1, B1 } & \multicolumn{3}{|c|}{$A 1 、 A 2$} & \multicolumn{3}{|c|}{$A 1 、 A 2 、 B 1$} \\
\hline \multirow{2}{*}{\multicolumn{2}{|c|}{ TSC switching state }} & \multirow{2}{*}{\multicolumn{3}{|c|}{ One bank in A-phase }} & \multirow{2}{*}{\multicolumn{3}{|c|}{$\begin{array}{l}\text { One bank in A-phase, } \\
\text { One bank in B-phase }\end{array}$}} & \multirow{2}{*}{\multicolumn{3}{|c|}{ Two banks in A-phase }} & \multirow{2}{*}{\multicolumn{3}{|c|}{$\begin{array}{l}\text { One bank in A-phase, } \\
\text { Two banks in B-phase }\end{array}$}} \\
\hline & & & & & & & & & & & & & \\
\hline \multirow{2}{*}{ Load-side } & Current value & 82.35 & 75.78 & 75.81 & 82.25 & 82.487 & 75.81 & 98.94 & 75.76 & 75.83 & 98.58 & 83.51 & 76.17 \\
\hline & \%PVIR & & $8.43 \%$ & & & $8.32 \%$ & & & $27.76 \%$ & & & $26.03 \%$ & \\
\hline \multirow{2}{*}{$\begin{array}{l}\text { Power supply- } \\
\text { side }\end{array}$} & Current value & 77.12 & 75.78 & 75.81 & 77.32 & 77.837 & 75.81 & 79.82 & 75.76 & 75.83 & 79.86 & 77.78 & 76.17 \\
\hline & \%PVIR & & $1.76 \%$ & & & $2.62 \%$ & & & $5.26 \%$ & & & $4.73 \%$ & \\
\hline
\end{tabular}

Note: A1 represents the first unbalanced load group in A-phase, B1 represents the first unbalanced load group in B-phase, A2 represents the second unbalanced load group in A-phase, the three current values represent the current in the A,B,C phase respectively.

\section{Table 2. Data sheet of power supply harmonic.}

\begin{tabular}{c|c|c|c|c|}
\hline $\begin{array}{c}\text { TSC switching } \\
\text { combination mode }\end{array}$ & none & $\begin{array}{c}\text { One bank of fifth } \\
\text { harmonic filter }\end{array}$ & $\begin{array}{c}\text { Two banks of fifth } \\
\text { harmonic filter }\end{array}$ & $\begin{array}{c}\text { Harmonic suppression } \\
\text { rate }\end{array}$ \\
\hline $\begin{array}{c}\text { Fifth harmonic current } \\
\text { in grid-side (A) }\end{array}$ & 40.7 & 23.54 & 14.37 & $64.70 \%$ \\
\hline
\end{tabular}

Then the three-phase current unbalanced level can be expressed by:

$$
\% P V I R=\frac{\max \left(I_{a}, I_{b}, I_{c}\right)-\min \left(I_{a}, I_{b}, I_{c}\right)}{I_{a v}} \times 100 \%
$$

As shown in the Table 1, we can see that when the un-balanced load occurred in the grid, the main controller can give TSC spilt-phase compensation units switching order according to the TSC's switching state and drastically reduce the current unbalanced level, with the intention of unbalanced compensation of The Device.

\subsubsection{Filter Test}

Reactors are connected in series with the capacitors in the TSC branch to compose the filter, but it can only filter certain times harmonic, we take the fifth harmonic for example, Table 2 shows the rest harmonic current in the grid when the fifth harmonic with the current of $40.7 \mathrm{~A}$ was injected in the grid and two-TSC banks were switched on. We can see from the table that after two units TSC's switching, the rest harmonic current in the grid is $14.37 \mathrm{~A}$ and the harmonic suppression rate attains to $64.70 \%$, at the same time the test can verify the filter function of The Device.

\section{Conclusions}

The Device is a multifunctional compensation device with a high cost-performance rate, the field test and simulation in the RTDS system can verify that the device can realize the rapidly continuous reactive power compensation, at the same time has the ability to compensate unbalanced load, filter and harmonic prevention, so it is worth popularizing to improve power factor and power quality.

\section{REFERENCES}

[1] Z. A. Wang, J. Yang and J. J. Liu, "Harmonic Suppres- sion and Reactive Power Compensation,” Beijing: China Machine Press, 2005, pp.167-19.

[2] A. Luo, "Grid Harmonic Suppression and Reactive Power Compensation Technology and Equipment," Beijing: China Power Press, 2006, pp.183-221.

[3] Y. F. Li and Y. X. Ma, "Progress of Harmonic Suppression and Reactive Power Compensation Technology," Journal of Shaanxi University of Technology (Social Sciences), Vol. 25, No. 1, 2009.

[4] X. Q. Tong, W. J. Wu and B. Y. Ren, "The Application of Voltage-source Inverter in the Power System,” China Machine Press, pp.60-63.

[5] G. F. Guo, "The Application of Reactive Power Compensation in the Distribution System,” Power system technology, Vol. 31, No. 1, 2007, pp. 229-230.

[6] Q. Gong, “TSC Dynamic Reactive Power Compensation Technology and Its Application,” Power system technology, Vol. 31, No. 2, 2007, pp.118-122.

[7] X. Q. Tong, Q. F. Wu and J. Yi, "The Research on the Control Method of STATCOM in Parallel Operation," Journal of Xi'an University of Technology, Vol. 24, No. 4, 2008.

[8] W. Zhao and A. Luo, "The Cooperation Operation of SVG and TSC in the System Proceeding of the CSEE 2009,” Vol. 29, No. 19, pp. 92 - 98.

[9] X. H. Ma, "Research on the DSTATCOM," Xi'an University of Technology, 2004.

[10] C. B. Luo, Y. Ji and Z. Y. Liu, "The Principle and Realization of the STATCOM,” China Power Press, 2005.

[11] H. S. Su and Q. Z. Li, "Rough Controlling TSC for Reactivecurrent Compensation in Traction Substations," Conference Proceedings of CES/IEEE 5th International Power Electronics andMotion Control Conference, Shanghai, 2006.

[12] H. W. Liu, "Research on the Parallel Operation of the Active Power Filter Based on the Capacity-limited Control Strategy,” Yan Shan University, 2007.

[13] X. L. Wei and K. Dai, "The Parallel Control of Active Power Filter in the Three-phase Three-wire System," Automation of Electric Power Systems, 2007.

[14] Z. Y. Yang and J. F. Zhao and G. Q. Tang, "Research on the Parallel Operation of the Active Power Filter Based on the Current-limited Control Strategy," Electric power Automation Equipment, Vol. 3, No. 26, 2006.

[15] W. Freitas and A. Morelato and Xu Wilsun, et al., "Impacts of AC Generators and DSTATCOM Devices on the Dynamic Performance of Distribution System," IEEE Transactions on Power Delivery, Vol. 20, No. 2, 2005, pp.1493-1501.doi:10.1109/TPWRD.2004.839181

[16] R. Esmaili, L. Xu and D. K. Nichols, “A New Control Method of Permanent Magnet Generator for Maximum Power Tracking in Wind Turbine Application," IEEE Power Engineering Society General Meeting, Vol. 3, No. 12-16, 2005, pp. 2090 - 2095.

[17] S. Ponnaluri, J. K. Steinke, P. Steimer, S. Reichert and B. Buchmann, "Design Comparison and Control of Medium 
Voltage STATCOM with Novel Twin Converter Topology," $35^{\text {th }}$ Annul IEEE Power Electronics Specialists Conference, 2004.

[18] M. S. ElMoursi, Prof. Dr. A. M.Sharaf, "Voltage Stabili- zation And Reactive Compensation Using A Novel FACTS-STATCOM Scheme,” IEEE CCECE/CCGEI, Saskatoon, May 2005. 